\title{
Antiemetic effect of propofol administered at the end of surgery in laparoscopic assisted vaginal hysterectomy
}

\author{
Eu-Gene Kim, Hye Jin Park, Hyoseok Kang, Juyoun Choi, and Hyun Jeong Lee \\ Department of Anesthesiology and Pain Medicine, Eulji General Hospital, Eulji University College of Medicine, Seoul, Korea
}

Background: Postoperative nausea and vomiting (PONV) commonly occur after general anesthesia, especially in women. In this study, we evaluated the antiemetic efficacy of propofol administered at the end of surgery in highly susceptible patients undergoing a laparoscopy-assisted vaginal hysterectomy.

Methods: A total of 107 women undergoing a laparoscopy-assisted vaginal hysterectomy under general anesthesia were enrolled for this prospective, double-blind, randomized study. Fifteen minutes before the end of surgery, all patients received $50 \mu \mathrm{g}$ fentanyl and 1 of following 3 doses; $0.5 \mathrm{mg} / \mathrm{kg}$ of propofol (propofol 0.5 group), $1 \mathrm{mg} / \mathrm{kg}$ of propofol (propofol 1.0 group), and normal saline (control group). All patients received intravenous patient-controlled analgesia (PCA). Emergence time, a visual analog scale for pain and nausea, duration of postanesthesia care unit (PACU) stay, and frequency of antiemetic use were recorded at 0-2, 2-24, and 24-48 hours postoperatively.

Results: The incidence of nausea significantly lower in the propofol 0.5 and propofol 1.0 groups than in the control group (12.1 vs 14.7 vs $40 \%$ ). During the first postoperative 2 hours, antiemetics were less frequently administered in the propofol 0.5 and propofol 1.0 groups than in the control group (3.0 vs 5.9 vs $22.5 \%$ ). Emergence time was slightly longer in the propofol 0.5 and propofol 1.0 groups than in the control group, but there was no significant difference in PACU stay time was observed between the 3 groups.

Conclusions: The results of this study suggest that low-dose propofol administration at the end of surgery may effectively reduce the incidence of PONV within 2 hours postoperatively in highly susceptible women undergoing a laparoscopiyassisted vaginal hysterectomy and receiving opioid-based PCA. (Korean J Anesthesiol 2014; 66: 210-215)

Key Words: Laparoscopy, Opioid, Postoperative nausea and vomiting, Propofol.

Received: August 6, 2013. Revised: 1st, August 22, 2013; 2nd, September 23, 2013. Accepted: September 26, 2013.

Corresponding author: Hye Jin Park, M.D., Ph.D., Department of Anesthesiology and Pain Medicine, Eulji General Hospital, College of Medicine, Eulji University, 280-1, Hagye-dong, Nowon-gu, Seoul 139-230, Korea. Tel: 82-2-970-8084, Fax: 82-2-970-8350, E-mail: anesthjin@hanmail.net (a) This is an open-access article distributed under the terms of the Creative Commons Attribution Non-Commercial License (http:// creativecommons.org/licenses/by-nc/3.0/), which permits unrestricted non-commercial use, distribution, and reproduction in any medium, provided the original work is properly cited. 


\section{Introduction}

Postoperative nausea and vomiting (PONV) which frequently occurs after general anesthesia needs prevention and treatment. Apart from unpleasant experience in patients, PONV carries multiple potential medical risks, such as gastric aspiration, wound dehiscence, and delayed discharge from post-anesthesia care units [1].

The etiologies of PONV after general anesthesia are complicated. Signals from variable areas in the central nervous system (visual, vestibular center, and chemoreceptor trigger zones) stimulate the emetic center. Afferents from the pharynx, gastrointestinal tract, and mediastinum also stimulate the emetic center [2].

Propofol has been reported to be an effective antiemetic at low doses in patients undergoing anticancer therapy [3] and surgery [4-6] in many articles, but the precise mechanism by which propofol works as an antiemetic is unclear [2]. In this study, we evaluated the preventive antiemetic efficacy of different doses of propofol administered 15 minutes before the end of surgery without delaying emergence in middle aged females undergoing laparoscopic gynecologic surgery and receiving opioid-based intravenous patient controlled analgesia (PCA).

\section{Materials and Methods}

After obtaining approval from the Institutional Review Board for our prospective, double-blind, randomized study, 107 healthy women underwent a laparoscopy-assisted vaginal hysterectomy under general anesthesia. Written informed consent to the study was obtained from each patient the day before sur- gery. All patients belonged to the American Society of Anesthesiologist I or II. Exclusion criteria included history of allergies to any study medications, gastrointestinal disease, insulin-dependent diabetes mellitus, administration of antiemetics or steroids 24 hours prior to surgery, cardiac diseases, neurological diseases, and impaired hepatic/renal function. No significant differences in demographic data were observed among individual subjects (Table 1).

Patients were randomly allocated to 3 groups using a computerized randomization table: those who received $0.5 \mathrm{mg} / \mathrm{kg}$ of propofol (propofol 0.5 group, $\mathrm{n}=33$ ), those who received 1.0 $\mathrm{mg} / \mathrm{kg}$ of propofol (propofol 1.0 group, $\mathrm{n}=34$ ), and those who received normal saline (control group, $n=40$ ). All patients were premedicated with diazepam ( $7 \mathrm{mg}$, oral) 1 hour before surgery. Upon arrival at the operating room, preoperative anxiety was evaluated by an anesthesiologist, who was blinded to the study groups, using a 4-point scale. For induction of anesthesia, intravenous propofol $2 \mathrm{mg} / \mathrm{kg}$ and intravenous rocuronium 0.8 $\mathrm{mg} / \mathrm{kg}$ was administrated to facilitate intratracheal intubation. After induction, anesthesia was maintained with 1.0-3.0 vol\% sevoflurane and $50 \%$ nitrous oxide in oxygen. Ventilation was mechanically controlled and adjusted to maintain an end-tidal $\mathrm{CO}_{2}$ concentration of $35-40 \mathrm{mmHg}$, and esophageal temperature was maintained at $36 \pm 1^{\circ} \mathrm{C}$ using a forced-air warming blanket during surgery. For appropriate muscle relaxation, vecuronium was administered as required.

Fifteen minutes before the end of surgery, patients received normal saline or propofol at 2 different doses, $0.5 \mathrm{mg} / \mathrm{kg}$ or 1 $\mathrm{mg} / \mathrm{kg}$ with fentanyl $(50 \mu \mathrm{g})$ in addition to being connected to a PCA. Injected drugs were prepared in identically shaped syringes covered with black transparent plastic by persons not

Table 1. Patient Demographics

\begin{tabular}{|c|c|c|c|}
\hline & $\begin{array}{l}\text { Control } \\
(\mathrm{n}=40)\end{array}$ & $\begin{array}{l}\text { Propofol } 0.5 \\
\quad(\mathrm{n}=33)\end{array}$ & $\begin{array}{l}\text { Propofol } 1.0 \\
\quad(\mathrm{n}=34)\end{array}$ \\
\hline Age (yr) & $45.5 \pm 5.5$ & $44.5 \pm 5.8$ & $46.0 \pm 6.7$ \\
\hline Height $(\mathrm{cm})$ & $159.0 \pm 5.2$ & $155.2 \pm 6.9$ & $157.3 \pm 4.8$ \\
\hline Weight $(\mathrm{kg})$ & $57.3 \pm 7.5$ & $60.2 . \pm 6.3$ & 59.6. \pm 6.8 \\
\hline Duration of anesthesia (min) & $111.2 \pm 44.2$ & $125.0 \pm 49.2$ & $121.0 \pm 54.1$ \\
\hline Input (ml) & $1261.0 \pm 624.3$ & $1023.1 \pm 533.8$ & $937.1 \pm 430.9$ \\
\hline Hx of PONV or motion sickness & 9 & 7 & 8 \\
\hline No of Non-smoker & 38 & 28 & 30 \\
\hline \multicolumn{4}{|l|}{ Menstrual cycle } \\
\hline $0-6$ & 0 & 0 & 0 \\
\hline $7-17$ & 15 & 14 & 12 \\
\hline$>17$ & 20 & 16 & 18 \\
\hline Postmenopausal & 5 & 3 & 4 \\
\hline \multicolumn{4}{|l|}{ Anxiety } \\
\hline None & 1 & 3 & 5 \\
\hline Mild & 30 & 21 & 21 \\
\hline Moderate & 9 & 9 & 8 \\
\hline
\end{tabular}

Values are means \pm SD or number of patients. PONV: postoperative nausea and vomiting. There were no significant differences between the 3 groups. 
Table 2. Postoperative Pain Scores and Emergence Time

\begin{tabular}{lccc}
\hline & $\begin{array}{c}\text { Control } \\
(\mathrm{n}=40)\end{array}$ & $\begin{array}{c}\text { Propofol } 0.5 \\
(\mathrm{n}=33)\end{array}$ & $\begin{array}{c}\text { Propofol 1.0 } \\
(\mathrm{n}=34)\end{array}$ \\
\hline VAS & & & \\
$0-2 \mathrm{~h}$ & $6.7 \pm 1.8$ & $6.4 \pm 2.3$ & $6.2 \pm 2.9$ \\
$12-24 \mathrm{~h}$ & $5.3 \pm 1.6$ & $4.9 \pm 2.1$ & $5.1 \pm 1.7$ \\
$24-48 \mathrm{~h}$ & $1.6 \pm 0.9$ & $1.5 \pm 1.2$ & $1.8 \pm 1.4$ \\
Additional fentanyl in PACU ( $\mu \mathrm{g})$ & $40.0 \pm 38.1$ & $47.3 \pm 39.1$ & $45.3 \pm 37.6$ \\
Time to extubation (min) & $11.2 \pm 3.8$ & $13.8 \pm 5.1 *$ & $14.6 \pm 6.5^{*}$ \\
Time to discharge PACU (min) & $55.1 \pm 21.6$ & $54.1 \pm 20.3$ & $59.1 \pm 18.3$ \\
\hline
\end{tabular}

Values are means \pm SD. VAS: visual analog score for pain evaluation. *Indicates $\mathrm{P}<0.05$ compared to the control group: the propofol 0.5 group ( $\mathrm{P}=$ $0.038)$ and the propofol 1.0 group $(\mathrm{P}=0.006)$.

involved in the study. The PCA regimen consisted of $1,050 \mu \mathrm{g}$ of fentanyl and $150 \mathrm{mg}$ of ketorolac (total volume including saline, $100 \mathrm{ml}$ ) and was programmed to a $2 \mathrm{ml} / \mathrm{h}$ basal infusion and 2 $\mathrm{ml}$ on demand with a 15 minutes lockout time. Sevoflurane was discontinued at the completion of surgery. Glycopyrrolate (0.04 $\mathrm{mg}$ ) and pyridostigmine $(15 \mathrm{mg}$ ) were administered intravenously to facilitate the reversal of muscle relaxation. The endotracheal tube was removed when the patient was spontaneously breathing and was able to open her eyes on command. Emergence time was defined as time from discontinuation of sevoflurane to extubation. After extubation, patients were transferred to the post-anesthesia care unit (PACU).

Nausea was defined as a subjectively unpleasant sensation associated with awareness of the urge to vomit, and vomiting was defined as the forceful expulsion of gastric contents from the mouth [1]. For the evaluation of the severity of nausea and postoperative pain, a visual analog score (VAS) was used. Ramosetron $(0.3 \mathrm{mg})$ was administered intravenously when a patient complained of persistent nausea (VAS for nausea $>5$ ), developed vomiting ( $>1$ episode) or needed another rescue antiemetic in the PACU. Fentanyl $(50 \mu \mathrm{g})$ was administered intravenously if a VAS for pain was $>5$ or if a patient needed an additional rescue agent. To avoid delay in treatment of pain or PONV, there was a detailed description of rescue antiemetic or opioid at a preanesthetic visit. When patients satisfied the discharge criteria of the PACU, they were transferred to the ward, and the stay time in the PACU was recorded. To evaluate recovery from anesthesia, the aldrete recovery score was used. Oxygen saturation, consciousness, circulation, respiration, and motor activity were accessed in the 3 grading systems $(0,1$, and 2$)$ by the anesthesiology staff. The patients were discharged when a score of $>9$ (total 10) was reached [7]. All PONV episodes were recorded through direct interviews by a single anesthesiologist who was blinded to patient groups or through patient complaint of PONV during the postoperative $0-2,2-24$, and 24-48 hours.

SPSS (version18.0) to analyze data (version 18.0), and SigmaStat 12.0 is used to decide sample size. Statistical analyses were

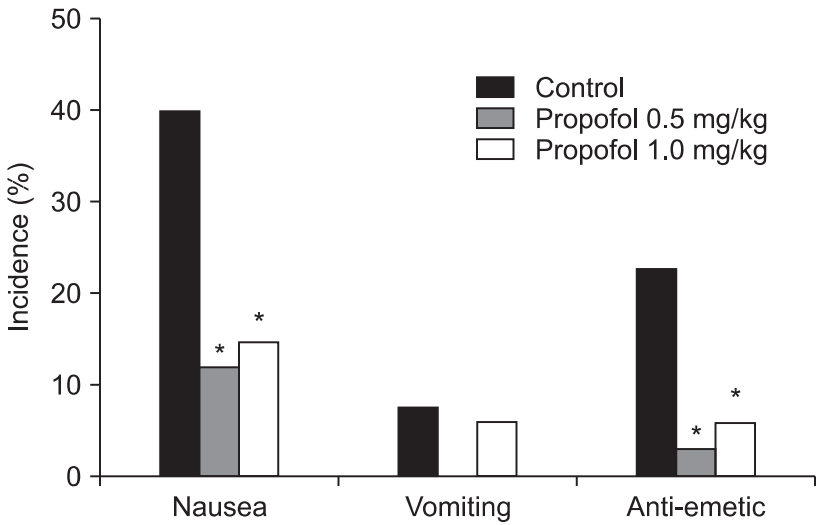

Fig. 1. The incidence of nausea and the number of rescue antiemetics are significantly lower in the propofol 0.5 and propofol 1.0 groups than in the control group during postoperative 2 hours. ${ }^{*} \mathrm{P}<0.05$ compared to the control group.

performed using the Chi-square test and Fisher's exact test for categorical data and one-way ANOVA for continuous data. A P value of $<0.05$ was considered significant. A sample size of $>102$ decided to have an $80 \%$ power $(\beta=0.20)$ of detecting a $28-30 \%$ reduction in PONV from basal incidence $40 \%(\alpha=0.05)$ on the basis of the preliminary study in Chi-square analysis. Values are expressed as means \pm SD or number of patients (\%).

\section{Results}

No significant differences were observed in preoperative anxiety (Table 1), postoperative pain (VAS), or the rescue fentanyl dose (Table 2) between the 3 groups. Emergence time was slightly longer in the propofol 0.5 and propofol 1.0 groups in the control group, but no significant difference was observed PACU stay time.

The incidence of nausea for the first postoperative 2 hours after surgery was significantly lower in the propofol 0.5 and propofol 1.0 groups than in the control group (12.1 vs 14.7 vs 40.0\%) (Fig. 1). However, no significant differences were observed 
Table 3. Incidences of PONV and Anti-emetic Rescue

\begin{tabular}{lcccc}
\hline & $\begin{array}{c}\text { Control } \\
(\mathrm{n}=40)\end{array}$ & $\begin{array}{c}\text { Propofol 0.5 } \\
(\mathrm{n}=33)\end{array}$ & $\begin{array}{c}\text { Propofol 1.0 } \\
(\mathrm{n}=34)\end{array}$ & P value \\
\hline Nausea & & & & \\
$<2 \mathrm{~h}$ & 16 & 4 & 5 & $0.007^{*}$ \\
$2-24 \mathrm{~h}$ & 5 & 7 & 8 & 0.434 \\
$24-48 \mathrm{~h}$ & 2 & 3 & 2 & 0.793 \\
$\quad$ Total & 16 & 8 & 9 & 0.279 \\
Vomiting & & & & \\
$<2 \mathrm{~h}$ & 3 & 0 & 2 & 0.373 \\
$2-24 \mathrm{~h}$ & 3 & 3 & 5 & 0.623 \\
$24-48 \mathrm{~h}$ & 0 & 0 & 1 & 0.626 \\
Total & 3 & 3 & 5 & 0.623 \\
Anti-emetics & & & & \\
$<2 \mathrm{~h}$ & 9 & 1 & 2 & $0.026^{*}$ \\
$2-24 \mathrm{~h}$ & 2 & 6 & 7 & 0.095 \\
$24-48 \mathrm{~h}$ & 0 & 4 & 3 & 0.053 \\
Total & 10 & 10 & 12 & 0.863 \\
\hline
\end{tabular}

Values are number of patients. *Indicates $\mathrm{P}<0.05$ between the 3 groups.

at 2-24 hours, $24-48$ hours, or throughout the study period. It was impossible to compare the severity of nausea between the 3 groups because of low incidence of nausea in the propofol 0.5 and propofol 1.0 groups. No significant differences in the incidence of vomiting were observed throughout the study period.

The number of patients who received a rescue antiemetic was smaller during the first postoperative 2 hours $(\mathrm{P}=0.026)$ in the propofol 0.5 and propofol 1.0 groups than in the control group, but tended to become higher during $2-24$ hours $(\mathrm{P}=0.095)$ and 24-48 hours $(\mathrm{P}=0.053)$. No differences were observed in the number of patients who received a rescue antiemetic throughout the study period (Table 3, Fig.1).

\section{Discussion}

We demonstrated a significantly lower incidence of nausea and number of rescue antiemetics in the propofol 0.5 and propofol 1.0 groups than in the control group during the first postoperative 2 hours. There were no significant differences in propofol doses.

PONV may result in a long-term hospital stay and increased treatment costs and affect the satisfaction of patients who received anesthesia. Nevertheless, the etiologies of PONV after surgery under general anesthesia are complex and not fully understood. Apfel et al. [8] reported that female gender, prior history of motion sickness or PONV, non-smoker, and use of postoperative opioids are the most important predictors of PONV. Additionally, the incidence of nausea and vomiting is much higher in women undergoing gynecologic laparoscopic surgery than in those undergoing other surgical procedures (67 vs $20 \%$ ) $[1,9,10]$.

Propofol has been universally accepted as an anesthetic since its approval by the Food and Drug Administration and introduction into clinical practice in 1989 [11]. Although propofol was initially accepted as an induction and maintenance hypnotic agent, its clinical use has remarkably expanded over the past 30 years. In this study, we focused on unique antiemetic properties of propofol. The mechanisms of antiemetic effects are not completely elucidated. Many investigators have conducted a variety of studies to identify the mechanism. Ostman et al. [12] found that the antiemetic effect of propofol is not attributed to lipid emulsion used to solubilize the drug. Borgeat et al. [4] reported that propofol does not have vagolytic properties. In a study by Hammas et al. [13], propofol reduces the intensity of retching after oral intake of ipecacuanha syrup, which releases 5-hydroxytryptamine. It is concluded that propofol may have a serotonin antagonistic effect. Propofol decreased synaptic transmission in the olfactory cortex in an animal study, suggesting a decrease in the release of excitatory amino acids such as glutamate and aspartate, which may be related to its antiemetic activity [14].

Numerous studies have identified appropriate dosages for the antiemetic effect of propofol. Borgeat et al. [3] used a 17 $\mu \mathrm{g} / \mathrm{kg} / \mathrm{min}$ propofol infusion in a group of patients receiving cisplatinum chemotherapy. Schulman et al. [15] indicated that the plasma concentration of propofol to treat refractory PONV is $197 \mathrm{ng} / \mathrm{ml}$. Because this is a case report, further studies are needed for generalization. Borgeat at al. [4] administered a bolus of propofol (10-20 mg) for the treatment of PONV in the recovery room. However, pain on injection of propofol may be uncomfortable to an awakening patient. Erdem et al. [5] reported that intraoperative infusion of $20 \mu \mathrm{g} / \mathrm{kg} / \mathrm{min}$ of propofol had a prophylactic antiemetic effect. Another study showed that $1.0 \mathrm{mg} / \mathrm{kg}$ of propofol at the end of surgery reduced both PONV and emergence agitation in children [6]. On the other hand, Kim et al. [16] reported that $0.5 \mathrm{mg} / \mathrm{kg}$ of propofol combined with dexamethasone was not effective in the prevention of PONV in pediatric patients with moyamoya disease.

Because our patients underwent relatively long duration surgery and received opioid-based PCA, we chose higher doses of propofol compared to those of previous studies and extended observation period until 48 hours postoperatively. In our study, propofol decreased the development of nausea during the first postoperative 2 hours, but had no effect at 2-24 hours, 24-48 hours, or throughout the study period, which may be related to pharmacokinetics of propofol. After an initial bolus of propofol, plasma levels decline rapidly as a result of redistribution and elimination. The initial distribution half-life of propofol is $2-8$ minutes, and the clearance rate is $20-30 \mathrm{ml} / \mathrm{kg} / \mathrm{min}$ [17]. Due to these properties, the plasma concentration of propofol may have diminished after 2 hours. This means that a single administration of propofol at the end of surgery could be not effective in patients receiving the opioid-based PCA. While intraoperative 
subhypnotic propofol infusion was effective during 24 hours postoperatively in patients without opioid-based PCA [5], total intravenous anesthesia with propofol was effective only during 6 hours postoperatively in patients with PCA [18]. For these patients, another treatment for PONV was needed. Propofol therapy is considered more useful for patients undergoing minor surgery, such as the outpatient-based laparoscopic procedure and tonsillectomy. However, exact propofol concentration having an antiemetic effect is still unknown [19]. Considering that various doses of propofol have been studied for the prevention of PONV, further studies on plasma concentration with antiemetic effect is required to solve this issue.

Interestingly, no significant differences were observed in the incidence of vomiting during the same period $(\mathrm{P}=0.373)$. As our study protocol allowed the administration of ramosetron to patients who felt nauseous (VAS > 5), the amount of ramosetron administered was higher in the control group than in the propofol 0.5 and propofol 1.0 groups $(P=0.026)$. The administration of ramosetron in patients who developed nausea may have depressed the development of vomiting and have blunted the differences between the 3 groups.

In contrast to the previous study [16], there was the prolongation of emergence time in the propofol 0.5 and propofol 1.0 groups compared to the control group $(\mathrm{P}<0.05)$. However, prolonged time was only 2.6-3.4 minutes, and it may not be significant in clinical practice.

In addition, this study did not compare the antiemetic effects of propofol with those of other drugs. Traditionally, dexamethasone, serotonin receptor antagonists, or several other drugs have been used to prevent and treat PONV [2]. Further investigations are required to evaluate the efficacy of propofol. Also, studies on synergistic or additional effects with other drugs are needed especially in high-risk patients.

In conclusion, administration of $0.5 \mathrm{mg} / \mathrm{kg}$ and $1.0 \mathrm{mg} / \mathrm{kg}$ of propofol at the end of surgery may effectively reduce the incidence of PONV with slight prolongation of emergence time within the first postoperative 2 hours in highly susceptible women undergoing laparoscopy-assisted vaginal hysterectomy and receiving opioid-based PCA.

\section{References}

1. Sinclair DR, Chung F, Mezei G. Can postoperative nausea and vomiting be predicted? Anesthesiology 1999; 91: 109-18.

2. Watcha MF, White PF. Postoperative nausea and vomiting. Its etiology, treatment and prevention. Anesthesiology 1992; 77: 162-84.

3. Borgeat A, Wilder-Smith OH, Wilder-Smith CH, Forni M, Suter PM. Propofol improves patient comfort during cisplatin chemotherapy. A pilot study. Oncology 1993; 50: 456-9.

4. Borgeat A, Wilder-Smith OH, Saiah M, Rifat K. Subhypnotic doses of propofol possess direct antiemetic properties. Anesth Analg 1992; 74: 539-41.

5. Erdem AF, Yoruk O, Alici HA, Cesur M, Atalay C, Altas E, et al. Subhypnotic propofol infusion plus dexamethasone is more effective dexamethasone alone for the prevention of vomiting in children after tonsillectomy. Paediatr Anaesth 2008 ;18: 878-83.

6. Kim MS, Moon BE, Kim H, Lee JR. Comparison of propofol and fentanyl administered at the end of anaesthesia for prevention of emergence agitation after sevoflurane anaesthesia in children. Br J Anaesth 2013; 110: 274-80.

7. Aldrete JA. The post-anesthesia recovery score revisited. J Clin Anesth 1995; 7: 89-91.

8. Apfel CC, Lärä E, Koivuranta M, Greim CA, Roewer N. A simplified risk score for predicting postoperative nausea and vomiting: conclusions from cross-validations between two centers. Anesthesiology 1999; 91: 693-700.

9. Kovac AL. Prevention and treatment of postoperative nausea and vomiting. Drugs 2000; 59: 213-43.

10. Koivuranta M, Läärä E, Ranta P, Ravaska P, Alahuhta S. Comparison of ondansetron and droperidol in the prevention of postoperative nausea and vomiting after laparoscopic surgery in women. A randomised, double-blind, placebo-controlled trial. Acta Anaesthesiol Scand 1997; 41: 1273-9.

11. Smith I, White PF, Nathanson M, Gouldson R. Propofol. An update on its clinical use. Anesthesiology 1994; 81: 1005-43.

12. Ostman PL, Faure E, Glosten B, Kemen M, Robert MK, Bedwell S. Is the antiemetic effect of the emulsion formulation of propofol due to the lipid emulsion? Anesth Analg 1990; 71: 536-40.

13. Hammas B, Hvarfner A, Thörn SE, Wattwill M. Effects of propofol on ipecacuanha induced nausea and vomiting. Acta Anaesthesiol Scand 1998; 42: 447-51.

14. Collins GG. Effects of the anesthetic 2,6-diisopropylphenol on synaptic transmission in the rat olfactory cortex slice. Br J Pharmacol 1988; 95: 939-49.

15. Shulman SR, Rockett CB, Canada AT, Glass PS. Long-term propofol infusion for refractory postoperative nausea: a case report with quantitative propofol analysis. Anesth Analg 1995; 80: 636-7.

16. Kim J, Jang GD, Kim DS, Min KT. Small dose of propofol combined with dexamethasone for postoperative vomiting in pediatric Moyamoya disease patients: a prospective, observer-blinded, randomized controlled study. Korean J Anesthesiol 2013; 64: 127-32. 
17. Hughes MA, Glass PS, Jacobs JR. Context-sensitive half-time in multicompartment pharmacokinetic models for intravenous anesthetic drugs. Anesthesiology 1992; 76: 334-41.

18. Yoo YC, Bai SJ, Lee KY, Shin S, Choi EK, Lee JW. Total intravenous anesthesia with propofol reduces postoperative nausea and vomiting in patients undergoing robot-assisted laparoscopic radical prostatectomy: a prospective randomized trial. Yonsei Med J 2012; 53: 1192-202.

19. Pavlin DJ, Coda B, Shen DD, Tschanz J, Nguyen Q, Schaffer R, et al. Effects of combining propofol and alfentanil on ventilation, analgesia, sedation, and emesis in human volunteers. Anesthesiology 1996; 84: 23-37. 